\title{
Lesiones múltiples por tenedor de mesa en el contexto de un homicidio
}

\author{
Multiple injuries by a table fork in a homicide
}

\author{
G. Font Valsecchi \\ $M$. Subirana Domènech
}

Médicos Forenses. Servei de Patologia Forense del Institut de Medicina Legal de Catalunya. (Barcelona)

Correspondencia: M. Subirana i Domènech Institut de Medicina Legal de Catalunya

Servei de Patologia Forense

Edifici G, 5 a planta

Gran Vía, 111

Barcelona 08014 E-mail: 25402msd@comb.cat

Fecha de recepción:

18.DIC.2012

Fecha de aceptación:

22.ENE.2013

\begin{abstract}
Resumen
Las lesiones por tenedor de mesa no son frecuentes en el contexto de un homicidio ya que no son potencialmente letales. Presentamos un caso de homicidio por múltiples lesiones de arma blanca en el que también se encontraron otras lesiones características de haber sido producidas por un tenedor de mesa.
\end{abstract}

Palabras clave: Patología forense. Autopsia. Heridas por arma blanca. Heridas por tenedor.

\section{Abstract}

Injuries by a table fork are uncommon in a homicide due to they are not potentially fatal. In this paper, a murder caused by multiple stab wounds and injuries by kitchen fork is presented.

Key words: Forensic pathology. Autopsy. Stab wounds injuries. Table fork injuries.

\section{Introducción}

En la investigación médico-legal de la muerte por parte del patólogo forense, los casos de homicidio son los más interesantes ya que suponen la integración de los datos del levantamiento con los derivados de la autopsia y de las pruebas complementarias que se hayan considerado necesarias.

En nuestro medio, el mecanismo homicida más frecuente es la agresión con arma blanca ${ }^{1}$, cuyo patrón lesivo es sobradamente conocido por todos los médicos forenses. No obstante, en ocasiones pueden solaparse otras heridas menos frecuentes como son las producidas por un tenedor de mesa.

\section{Presentación del caso}

Los ruidos procedentes de una pelea en un inmueble alertaron a los vecinos, quienes llamaron a la policía. Cuando llegan al domicilio, la dotación policial en- contró a una mujer de 58 años fallecida presuntamente como consecuencia de una agresión por parte de un familiar con antecedentes de trastorno psicótico.

En el lugar de la muerte se encontraron varios objetos compatibles con haber provocado la agresión: dos cuchillos, uno con la hoja curvada y otro con la hoja rota junto a un tenedor de mesa con dos de las puntas parcialmente dobladas (Figuras 1A y 1B).

Durante la autopsia se evidenciaron múltiples lesiones por arma blanca a nivel cervical y en cuero cabelludo así como hematomas indicativos de lesiones de defensa-lucha en el dorso de la mano derecha. La causa de muerte fue un shock hipovolémico como consecuencia de una herida por arma blanca a nivel cervical que seccionaba completamente la arteria carótida primitiva derecha (Figura 2 ). Además se encontraron a nivel craneal, del macizo facial derecho y del hombro homolateral unas heridas agrupadas en número de dos a cuatro, dispuestas en línea recta, redondeadas, espaciadas entre ellas por unos $0,5 \mathrm{~cm}$, superficiales y de bordes contusos. El patrón lesivo sugería que estas lesiones eran compatibles 
con haber sido producidas por el tenedor de mesa encontrado en la escena de la muerte (Figura 3). Aunque estas lesiones eran evidentes en algunas zonas, en las áreas lesivas en las que el tenedor había actuado de forma repetitiva y, por tanto, se solapaban, eran de más difícil interpretación (Figura 4).

\section{Discusión}

Las lesiones por tenedor de mesa son extremadamente raras en el contexto de un homicidio, principalmente porque no provocan heridas mortales como en el caso anteriormente expuesto.

Estas lesiones por tenedor se caracterizan porque son superficiales, tienen una longitud total de unos $2 \mathrm{~cm}$ cuando se han clavado todas las puntas y ocasionan grupos de cuatro heridas superficiales, de disposición rectilínea, redondeadas y con los márgenes contusos ${ }^{2}$.

En el caso descrito, si bien había zonas en las que se visualizaba con claridad el efecto de las cuatro puntas del tenedor, en otras sólo se evidenciaban patrones repetitivos de dos lesiones de disposición rectilínea, lo cual es compatible con el hecho de que estas lesiones se hubieran provocado por la acción continuada del tenedor cuando las puntas ya estaban dobladas. Llama la atención, en el caso objeto de discusión, el hecho de que se hubiera utilizado de forma repetitiva como arma un instrumento con escaso potencial letal. Este hecho quizá podría interpretarse como concordante con la patología psicótica del presunto agresor o bien como un intento de causar un mayor sufrimiento a la víctima.

Las reseñas bibliográficas e iconográficas de lesiones por tenedor de mesa son muy escasas y se circunscriben al ámbito médico asistencial. En este sentido se describen lesiones por tenedor en una autoenucleación ocular ${ }^{3}$ o como cuerpo extraño extraído del tubo digestivo ${ }^{4-8}$. Por este motivo, consideramos que el conocimiento de este patrón lesivo inusual puede ser extremadamente útil al médico forense que se enfrenta a ellas por primera vez.

\section{Agradecimientos}

Los autores queremos mostrar nuestro más sincero agradecimiento: al Dr. Ángel Cuquerella Fuentes, a los miembros de la Policía Científica de Mossos d'Esquadra y a los técnicos especialistas en patología forense del IMLC de Barcelona por su colaboración.

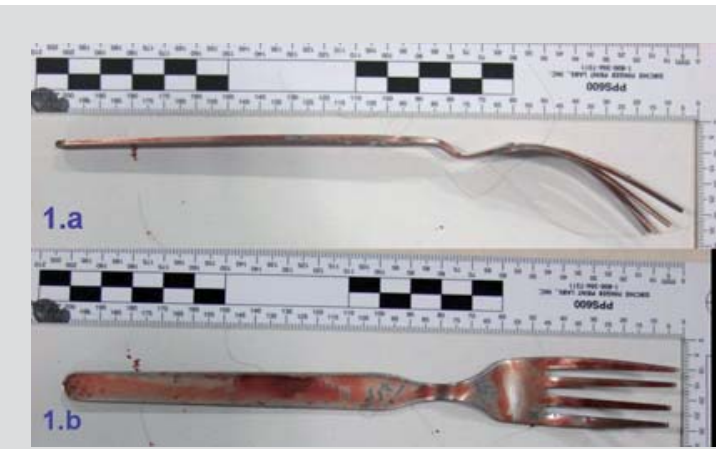

Figura $1 A$.

Visión lateral del tenedor de cocina, manchado de sangre y con las puntas dobladas.

Figura 1B.

Visión superior del tenedor.

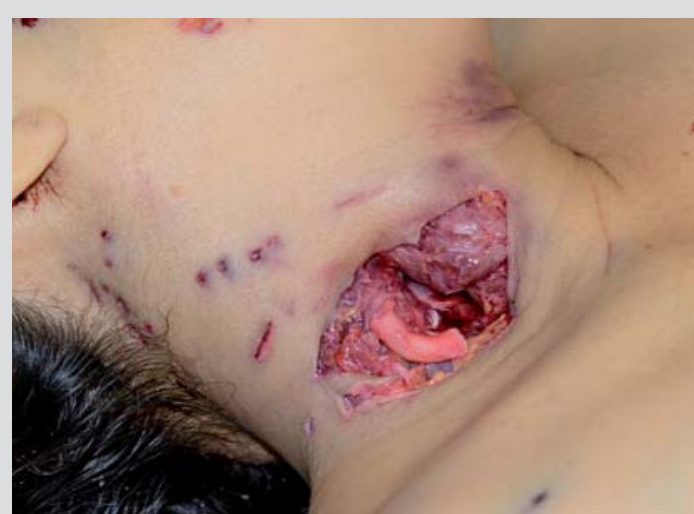

Figura 2.

Sección carotídea por lesión incisa en zona cervical lateral derecha provocada por arma blanca, lesiones superficiales por arma blanca periféricas y lesiones puntiformes provocadas por tenedor.

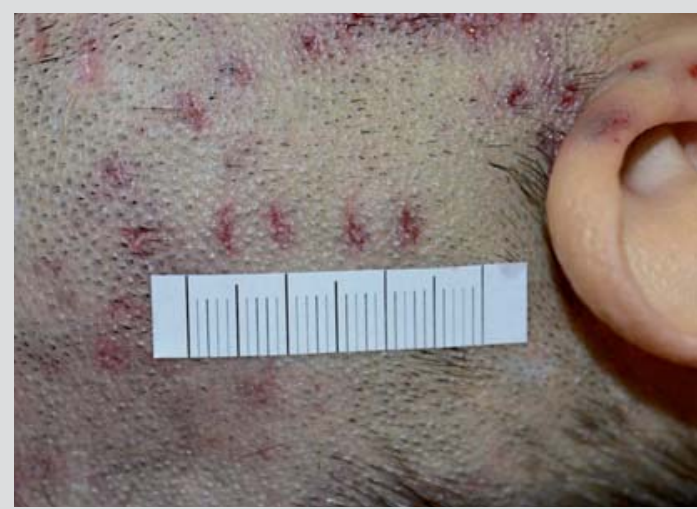

Figura 3.

Detalle de las lesiones provocadas por el tenedor de cocina.

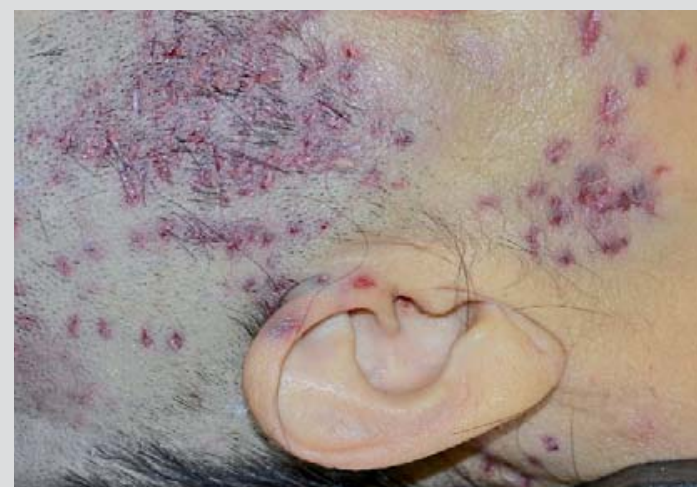

Figura 4.

Múltiples lesiones por tenedor en el macizo facial derecho y zona temporal homolateral. 


\section{Bibliografía}

1. Lucena J, García CA, Santos M, Rico A, Blanco M, Jiménez MP, et al. Estudio médico-legal del homicidio en la provincia de Sevilla (2004-2007): Especial referencia a los homicidios de mujeres en el contexto de violencia de género. Cuad Med Forense 2008;(51):35-46.

2. Sharp edged and pointed injuries. Cox W A, 2011. Disponible en: http://forensicmd.files.wordpress.com /2011/07/sharp-edged-and-pointed-instrumentinjuries1.pdf [consultado 13.12.2012]

3. Tabatabaei SA, Soleimani M, Khodabandeh A. A case of autoenucleation associated with a contralateral field defect. Orbit 2011;30(3):165-8.

4. Abrão J, Khabbaz KM, Abrão JM, Coutinho DJ, Juliano EA. Unusual foreign body in the esophagus: a challenge for the anesthesiologist. Acta Anaesthesiol Scand 2003;47(9):1176-7.
5. Yong PT, Teh CH, Look M, Wee SB, Tan JC, Chew SP, et al. Removal of a dinner fork from the stomach by double-snare endoscopic extraction. Hong Kong Med J 2000;6(3):319-21.

6. Atila K, Unek T, Sevinç Al, Aydoğan B, Serin A, Bora $\mathrm{S}$, et al. Delayed complete gastric outlet obstruction due to a dinner fork: report of a case. Ulus Travma Acil Cerrahi Derg 2010;16(4):376-8.

7. Karcz WK, Kulemann B, Seifert GJ, Schrag HJ, Küsters S, Marjanovic G, et al. Video. Laparoscopic extirpation of a fork from the duodenum. Surg Endosc 2011;25(7):2363.

8. Schenk C, Mugomba G, Dabidian RA, Scheuerecker $\mathrm{H}$, Glaser F. Laparoscopic extraction of a swallowed fork in a patient first diagnosed with bulimia nervosa. Surg Endosc 2002;16(2):361. 